\title{
The global crime drop and changes in the distribution of victimisation
}

\author{
Ken Pease ${ }^{1 *}$ and Dainis Ignatans ${ }^{2}$
}

\begin{abstract}
Over three decades crime counts in England and Wales, as throughout the Western world, have fallen. Less attention has been paid to the distribution of crime across households, though this is crucial in determining optimal distribution of limited policing resources in pursuing the aim of distributive justice. The writers have previously demonstrated that in England and Wales the distribution of crime victimisation has remained pretty much unchanged over the period of the crime drop. The present paper seeks to extend the study of changes in the distribution of victimisation over time using data from 25 countries contributing data to the International Crime Victimisation Survey (ICVS) sweeps (1989-2000). While fragmentary, the data mirror the trends discerned in England and Wales. The trends are not an artefact of the inclusion of particular countries in particular sweeps. The demographic, economical, geographical and social household characteristics associated with victimisation are consistent across time. The suggested policy implication is the need for greater emphasis on preventing multiple victimisation.
\end{abstract}

Keywords: Victimisation, Crime drop, Crime concentration, Distributive justice, Quantitative criminology

\section{Background}

Distributions are as important as measures of central tendency for applicable research. In the burgeoning literature on the near ubiquitous crime drop of recent years, an emphasis on distributions has arguably been lacking. Yet if (for example) the crime drop has been most marked for those who already suffered relatively little crime (as with regressive taxation) one would be concerned about the disproportionate burden which the most victimised continue to suffer. At the operational policing level, it is crucial to know how the diminished crime burden is distributed, so as to inform resourcing and deployment decisions. A recent paper (Ignatans and Pease 2015a) showed that the crime drop in England and Wales in recent years was greatest in absolute terms for the most victimised households, but not so great relative to the decline of crime generally as to yield a more even distribution of victimisation. The most victimised came to suffer fewer crimes, but these crimes represented a somewhat higher

*Correspondence: k.pease@ucl.ac.uk

1 Jill Dando Institute, University College London, 35 Tavistock Square, London WC1H 9EZ, UK

Full list of author information is available at the end of the article proportion of the total burden than before. Disaggregation by offence type (Ignatans and Pease 2015b) showed that the trends were for all practical purposes uniform across crime types.

The crime drop is common across nations. Are the distributional trends also similar cross-nationally? Early analyses of the crime drop were flawed in their exclusive concentration on trends in the USA. This led to the choice as explanatory variables which were specific to that country, such as prison use, police strength and abortion legislation. These variables trended differently in other countries with similar crime drops (Tonry 2014).

The intention here, insofar as the data permit, is to examine whether the trends identified in England and Wales extend beyond its borders. Is the slight increase in inequality of distribution of crime evident in England and Wales also evident elsewhere? The implications for crime control are substantial and will be touched upon in the "Conclusions".

\section{Main text}

For present purposes, four sweeps of the International Crime Victims Survey (ICVS) with a total representative adult sample of over 100,000 respondents over a decade 
were utilised. ICVS features victimisation reports over a recall period of 1 year that were gathered from 25 countries contributing data in at least one sweep. Thirteen of these countries featured in at least two sweeps. The data used in the analyses comes from countries that were surveyed nationally. Roughly 1000-2000 households were interviewed from each country over the phone (Netherlands Institute for Scientific Information Services 1999). Self-evidently trends require a minimum of two data points to discern so data from twelve countries had to be discarded. The fragmentary nature of the other data, and the fact that the most recent ICVS sweep was in 2000 when the crime drop had been under way for less than a decade, represented challenges. Given the unique nature of the ICVS data and the importance of the topic in the writers' view, it was a challenge worth accepting.

By taking into account the four-year time elapsing between sweeps, national data present in two or more datasets was deemed sufficient for substantive comparisons of trends in victimisation concentration over time. Offences were coded identically in all the sweeps, permitting consistent comparison across time. All thirteen countries are used in the global analyses (Figs. 1, 2, 3, 4, $5,6)$.

Multiple events against the same victim in ICVS are capped to a maximum of five for each offence type. If, for example, someone reports having been assaulted twenty times, the number of assaults is recorded as five. This convention compromises accuracy. The writers' analyses utilising the Crime survey for England and Wales (CSEW) with unlimited incident reporting show many victimisation repeats above the cut-off point of five. The underrepresentation of chronic victims in crime surveys

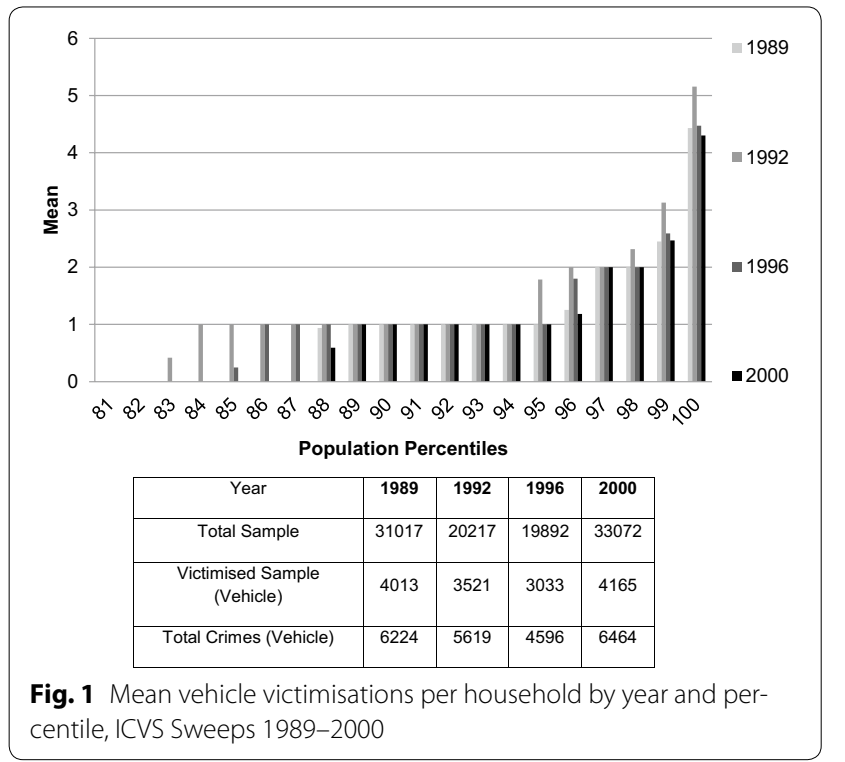

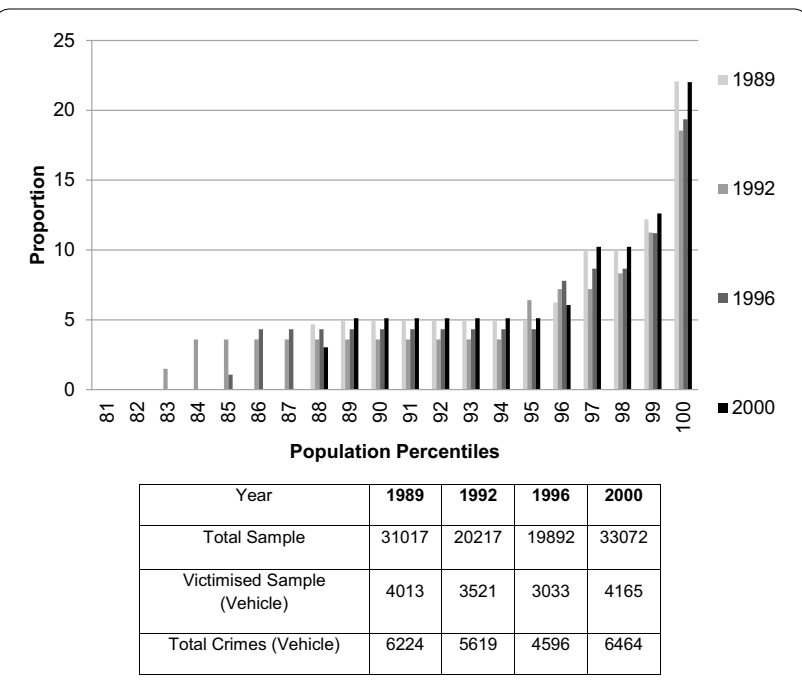

Fig. 2 Proportion of total vehicle victimisations by year and percentile, ICVS Sweeps 1989-2000

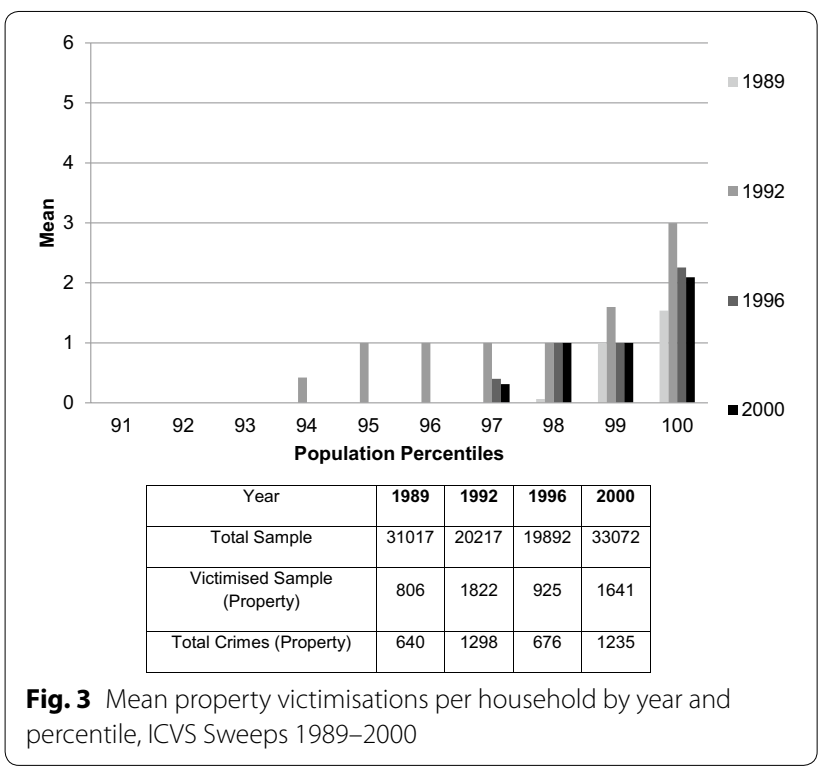

is controversial (Farrell and Pease 2007; Lauritsen et al. 2012). The pre-imposed ICVS five-count threshold was by necessity retained. The reader should be aware that by doing so the extent of chronic victimisation, and hence the inequality of victimisation, is understated.

When considering measurement of victimisation inequality, a slightly amended approach from that of Lorenz (1905) was adopted. Households were ranked by number of victimisations suffered, the ranked households divided into percentiles, and number of victimisations per percentile for each year calculated. Each percentile's crime could then be expressed as a proportion of the year's total 


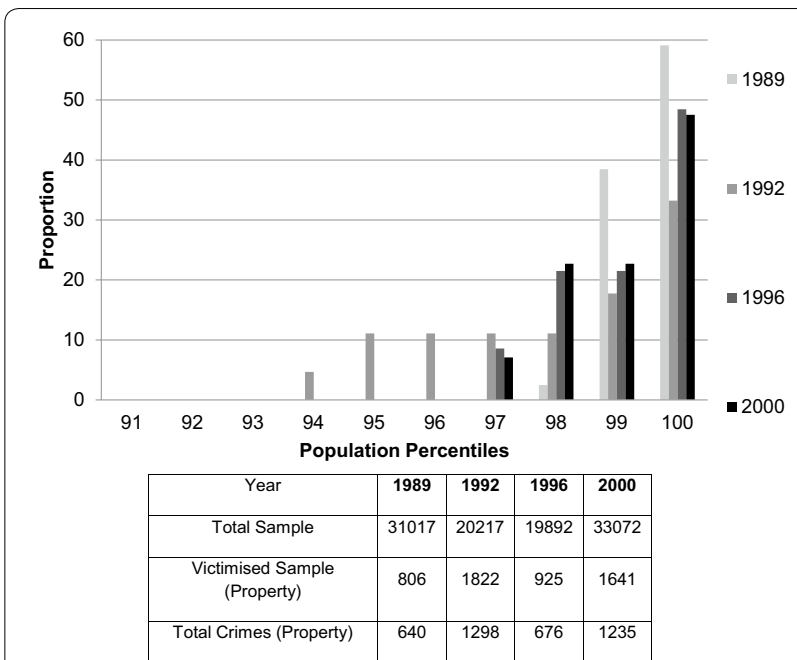

Fig. 4 Proportion of property victimisations by year and percentile, ICVS Sweeps 1989-2000

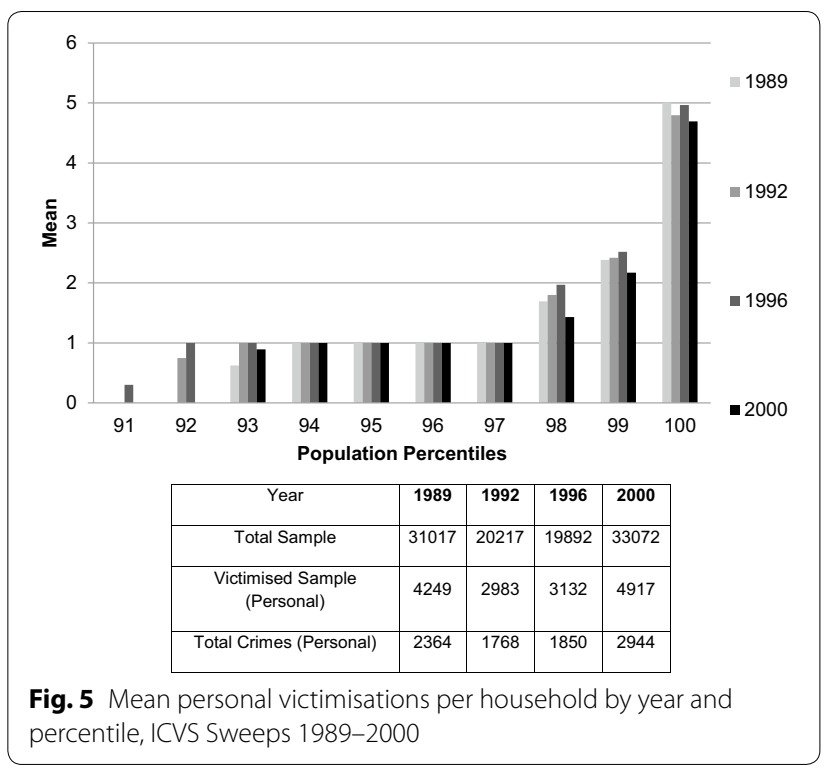

victimisations. This permits detailed comparison of ICVS sweeps and countries.

As noted earlier, Ignatans and Pease (2015b) showed the basic patterns in England and Wales to be similar across crime types. The same approach was applied to ICVS where means and proportions of victimisations by percentile for each crime type.

The figures below thus represent two variables.

- Mean number of victimisations of a particular crime type suffered by the most victimised percentile, next most victimised, and so on.

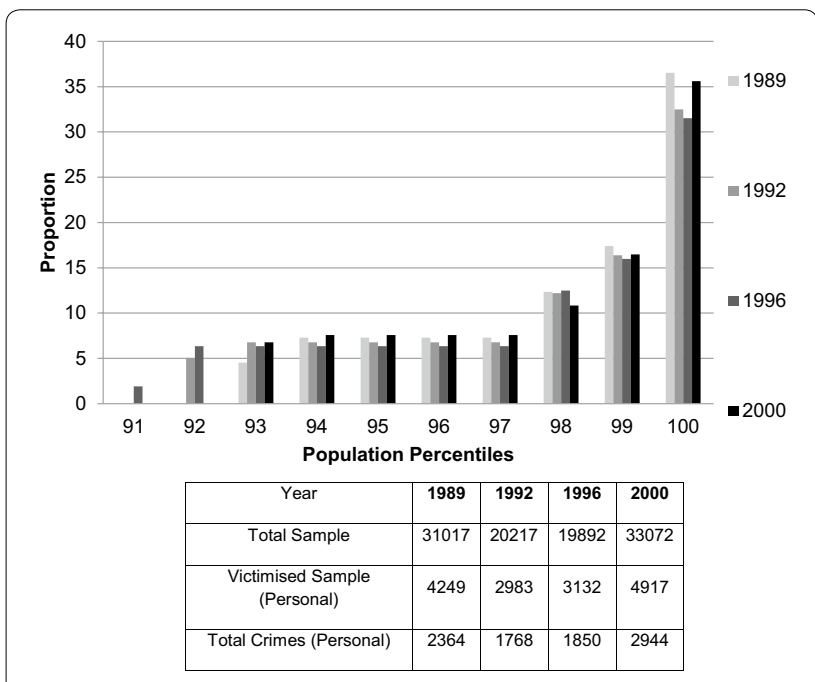

Fig. 6 Proportion of personal victimisations by year and percentile, ICVS Sweeps 1989-2000

- The proportion of all victimisations of that type suffered by the most victimised percentile, next most victimised, and so on.

\section{Results}

In all the figures the scales should be noted. They differ, being chosen to provide the clearest representation of the key part of the victimisation distribution. Offences were categorised in the appropriate categories in a fashion consistent with previous papers (Ignatans and Pease 2015a, 2015b) attributing all crimes that involve direct contact with the victim to the personal crime category, even where property was taken. Categories were constructed in the following fashion. Vehicle crimes: car theft, theft from car, damage to vehicle, motor vehicle theft, bicycle theft. Property crimes: burglary, attempted burglary, theft from garage. Personal crimes: robbery, personal theft, sexual offences, assault. Figure 1 depicts mean vehicle crimes by year. $82 \%$ of households suffered no vehicle crime so the abscissa starts at the 81 st percentile, It will be seen that the mean number of vehicle crime victimisations peaks then falls. This pattern is most marked for the most victimised $1 \%$ of households sampled where a drop of $16 \%$ is noted between the years of 1992 and 2000.

Figure 2 depicts the proportion of all vehicle crimes by percentile and ICVS sweep. A greater proportion of vehicle crime is suffered by the most victimised 1-2\% of households in 2000 than had been the case in the two preceding sweeps, and marginally more than in 1989. After an initial decline, the proportion of crimes in the tenth decile and especially top percentiles increased. 
An increase of 19 percent is seen in the last percentile between the years 1992 and 2000.

Parallel analyses for property crime are depicted as Figs. 3 and 4 and personal crimes as Figs. 5 and 6.

Property victimisations show the by now familiar decline in crime count and increase in proportion suffered by those most victimised. Property crime count fell by $30 \%$ in the last percentile while the proportion of victimisations attributed to the same households increased by 43 per cent between the years 1992 and 2000. The 1989 sample backs the trend both here and in the depiction of crimes against the person shown in Figs. 5 and 6.

The decline in crime counts and changes in proportion suffered by the most victimised is much less marked for crimes against the person than for other crime types. As evidenced by previous work (Tseloni et al. 2010, p 383) the drop in violent crime lagged behind the drop in other crime types and the last ICVS sweep came too early to capture the drop fully. Crime count experienced by the top percentile dropped by 5 per cent between the years 1996 and 2000 while the proportion of victimisations increased by 13 percent in the same time period.

The alert reader will note that the data could be skewed by countries with different characteristics participating in earlier relative to later sweeps. This was checked by looking at pairwise within country comparisons across sweeps. For example, comparing the first and fourth sweeps in respect of vehicle crime, how many countries exhibited a decrease in mean crime for the top percentile, and how many an increase? Likewise, how many countries exhibited an increase in proportion of crime for the top percentile and how many a decrease? Details of these analyses are available from the first author on request. Suffice it here to say that the decreased count slightly increased concentration pattern is common across countries and is not an artefact of which countries participated in which sweeps.

To recapitulate, the absolute victimisation of the most victimised has decreased internationally, as the proportion of victimisation suffered by the most victimised $1 \%$ of households has increased. After an initial decline in the early 1990s, the proportion of crimes attributed to the most victimised increased to just below a quarter for vehicle crimes, nearly a half for property crimes and over a third for personal offences.

The next step in the present paper addresses the question of whether the attributes of the heavily victimised households remain similar across time. There is already a substantial literature on attributes associated with crime victimisation (Tseloni et al. 2010; Kershaw and Tseloni 2005; Osborn and Tseloni 1998; Tseloni 2006), but these tend to be analyses at single points in time. Our previous papers examined a number of characteristics available in
British data. The only other empirical study of which we are aware which concerns equity if distribution of crime events during the crime drop was the study of domestic burglary of James Hunter and Andromachi Tseloni (2016). Here the question is whether the variables which distinguish the most victimised households and individuals in 1989 are the same as those which distinguish the most victimised in 2000 . The conclusion reached is that the risk factors of 2000 are similar to the risk factors of 1989. Bear in mind that the present analysis says nothing directly about area effects, which will also inform prioritisation of crime prevention effort (Tseloni 2006; Kershaw and Tseloni 2005; Osborn and Tseloni 1998) (Table 1).

Probabilities matter little with the sample sizes available. The important point is the consistency of the findings, as the characteristics associated with highly victimised are consistent across the 12 years of data available from the ICVS. Households with less favourable economic, geographic and demographic characteristics are consistently experiencing an overwhelmingly greater proportion of victimisation.

\section{Conclusions}

Considering the convergence of patterns found in previous analyses limited to England and Wales and the current international investigation, it appears that with little doubt the cross-national crime drop can be seen as the product of a drop in the count alongside a change in the distribution of crime across households. Around half of all property victimisation is suffered by the $1 \%$ of households which are most victimised, as is about one third of personal victimisation. The greater proportion of property relative to personal victimisation differs from the British picture, and is suspected to be an artefact introduced by the capping of crime events. If there are many victims of multiple personal crimes, this reversal of effect would be the result. Research which is urgently necessary and has been absent from the victimisation survey literature to date has been follow-up interviews with those multiply victimised to confirm the veracity of their accounts. For those accusing multiple victims of confabulation, the question why this confabulation should have declined over time in line with decreased crime counts.

The practical implication made in previous papers should simply be reiterated here. The concentration of crime prevention effort and resources should be directed at those already victimised. This is even more the case now than was the case before the onset of the crime drop. Repeat victimisation is most likely to occur and (reoccur the most) in households with less favourable economic, geographical and demographic factors, therefore police attention and prevention efforts must be directed towards such households experiencing first victimisation (Tseloni and Pease 2014, 2015). 


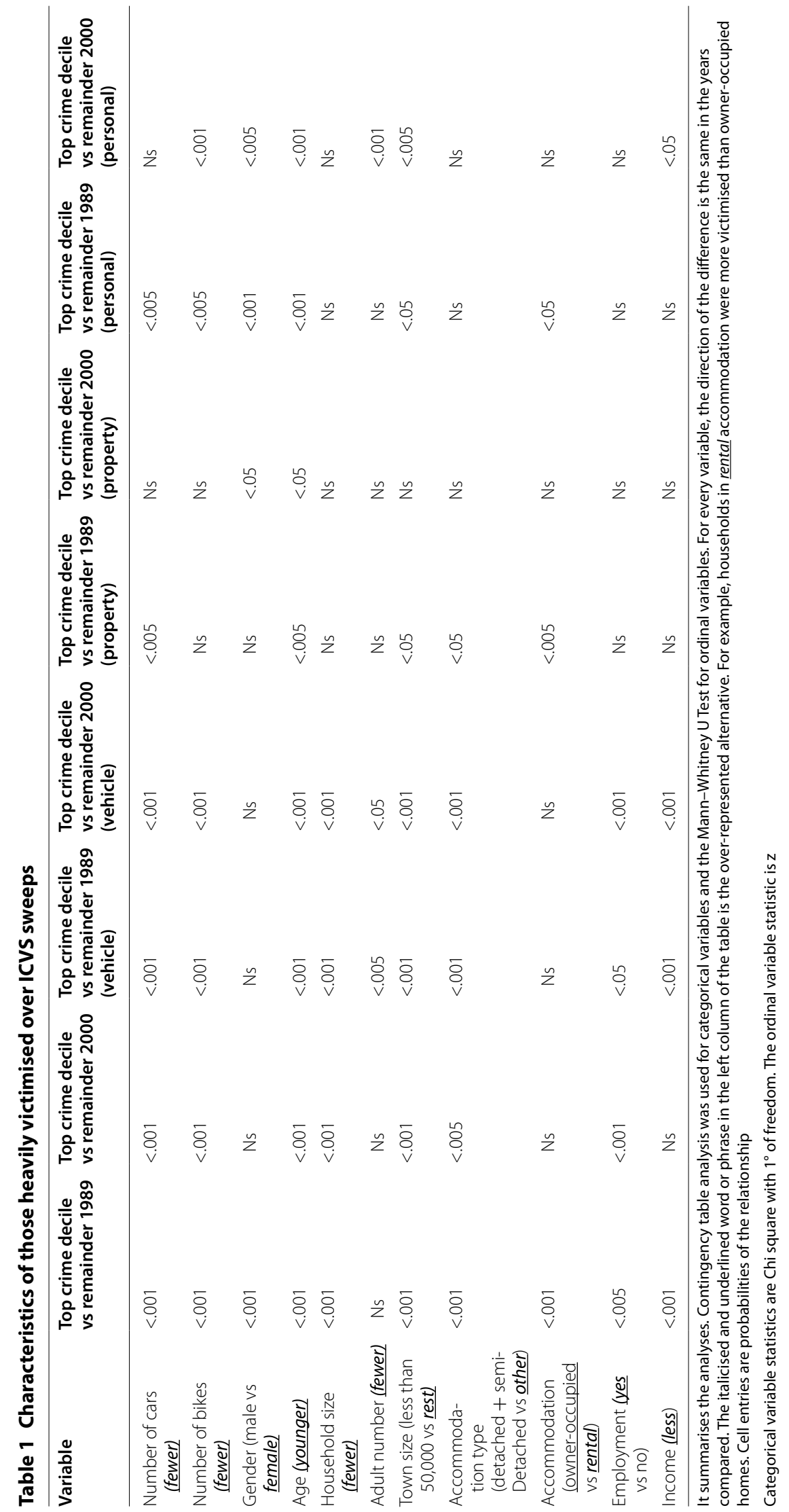




\section{Authors' contributions}

KP has conceived of the study, participated in the design of the paper and drafted the manuscript. DI carried out the necessary statistical analyses and helped to draft the manuscript. Both authors read and approved the final manuscript.

\section{Author details}

1 Jill Dando Institute, University College London, 35 Tavistock Square, London WC1H 9EZ, UK. ${ }^{2}$ University of Huddersfield, London, UK.

\section{Competing interests}

The authors declare that they have no competing interests.

Received: 17 December 2015 Accepted: 22 September 2016

Published online: 27 September 2016

\section{References}

Farrell, G., \& Pease, K. (2007). The sting in the tail of the British crime survey: multiple victimisations. In M. Hough \& M. Maxfield (Eds.), Surveying crime in the 21 st century. Cullompton: Willan.

Hunter, J., \& Tseloni, A. (2016). Equity, justice and the crime drop: the case of Burglary in England and Wales. Crime Sci, 5(1), 1.

Ignatans, D., \& Pease, K. (2015a). Distributive justice and the crime drop. In M. Andresen \& G. Farrell (Eds.), The criminal act: festschrift for Marcus Felson. London: Palgrave Macmillan.

Ignatans, D., \& Pease, K. (2015b, in press). On whom does the burden of crime fall now? Changes over time in counts and concentration. Int Rev of victimol.
Kershaw, C., \&Tseloni, A. (2005). Predicting crime rates, fear and disorder based on area information: evidence from the 2000 British crime survey. Int Rev Victimol, 12, 295-313.

Lauritsen, J., Gatewood Owens, J., Planty, M., Rand, M. R., \&Truman, J. L. (2012). Methods for counting high-frequency repeat victimizations in the national crime victimization survey. Washington DC: Bureau of Justice Statistics.

Lorenz, M. O. (1905). "Methods of measuring the concentration of wealth". Publications of the American Statistical Association (Publications of the American Statistical Association, Vol. 9, No. 70) 9(70): 209-219.

Netherlands Institute for Scientific Information Services (1999). Steinmetz Archive documentation set version 1.0, Den Haag

Osborn, D., \& Tseloni, A. (1998). The distribution of household property crimes. Journal of Quantitative Criminology, 14, 307-330.

Tonry, M. (2014). Why crime rates are falling throughout the Western World. Crime Justice, 43, 1-63.

Tseloni, A. (2006). Multilevel modelling of the number of property crimes: household and area effects. J Royal Stat Soc Ser A Stat Soc, 169, 205-233.

Tseloni, A., \& Pease, K. (2014). Using modelling to predict and prevent victimisation. New York: Springer.

Tseloni, A., \& Pease, K. (2015). Area and individual differences in personal crime victimisation incidence: the role of individual, lifestyle/routine activities and contextual predictors. Int Rev Victimol, 21(1), 3-29.

Tseloni, A., Mailley, J., Farrell, G., \& Tilley, N. (2010a). Exploring the international decline in crime rates. Eur J Criminol, 7(5), 375-394.

Tseloni, A., Ntzoufras, I., Nicolaou, A., \& Pease, K. (2010b). Concentration of personal and household crimes in England and Wales. Eur J App/ Math $21,326-348$.

\section{Submit your manuscript to a SpringerOpen ${ }^{\odot}$ journal and benefit from:}

- Convenient online submission

- Rigorous peer review

- Immediate publication on acceptance

- Open access: articles freely available online

- High visibility within the field

- Retaining the copyright to your article

Submit your next manuscript at springeropen.com 